\title{
Editorial: Wherein the articles of this issue and some new developments for TRI are introduced
}

In the summer of 2007 the annual conference of the International Federation of Theatre Research (IFTR/FIRT) met for the first time in Africa. Hosted by Stellenbosch University in South Africa, it was probably the first international theatre conference of its kind on the continent, enabling scholars and practitioners from all over the world as well as from many African countries to present their work on the conference theme: 'Theatre in Africa - Africa in the Theatre'. This issue of TRI opens with two articles which reflect the deep interest among non-African scholars in the latest developments on African stages as well as the challenge of depicting its complex state of affairs from within. Both contributions examine strategies of subversion mobilized by theatre to create continuity and identity through different readings of the historical past.

The first article, by Nigerian author and scholar Femi Osifisan, whose plays have been performed in Africa as well as on other continents, is one of the keynote lectures from the Stellenbosch conference. He was not, however, given the opportunity to deliver the paper himself, because the South African authorities, who had received all the applications long in advance, did not issue his entry visa to South Africa until less than 24 hours before the talk itself was scheduled. The second article, which won the first prize in the annual New Scholar's Prize competition sponsored by the IFTR (http://www.firtiftr.org/firt/site/newscholars.jsp) is by Christina S. McMahon, a Ph.D. candidate from Northwestern University in the US, who is conducting research for her dissertation in Cape Verde, the West African nation off the Atlantic coast. These two articles, together with the two articles published in the first issue of Volume 32 of TRI (March 2007), presenting the South African dramatist John Kani's Nothing but the Truth and community theatre and HIV, present four very different perspectives on African theatre today. And these perspectives are complemented by the special issue of $\operatorname{TRI}(27,3$, October 2002) on South African theatre after apartheid which was edited by Loren Kruger.

The third article in this issue, by Stéphanie Bérard, deals with the integration of the historical past in postcolonial theatre on the Carribean island of Martinique, in a play by Patrick Chamoiseau based on Sophocles' Antigone. Bérard's contribution is clearly connected to the two articles about Africa and distinguishes between forms of adapting Western classics, thus allowing the theatre 'to move from the literary colonial heritage, a dominant culture imposed by the outside, to a reappropriation of this 
culture from the inside, based on the popular, oral traditions transmitted by the African ancestors'.

Two further articles deal directly with appropriations and adaptations of Western theatre in non-European contexts. Yvette Khoury presents a Lebanese adaptation of Shakespeare's Romeo and Juliet by Oussama al-Rahbani, where the local conditions of this country feature quite prominently. In her article Khoury addresses important issues concerning how this production depicts local (Lebanon), regional (Middle East) and global (worldwide) cultural exchanges, and asks, 'how should we position this Arabic adaptation of Romeo and Juliet in relation to the "metropolitan" field of Shakespearean studies?', highlighting political as well as social and religious problems of staging Shakespeare in the Middle East, in particular in post-civil war Lebanon. The article by Pürnur Uçar-Özbirinci, detailing a Turkish production of A Streetcar Named Desire, raises related concerns, focusing on theoretical issues of interculturalism, situated, just like Turkey today, on the complex borderline between national values and an international consciousness.

Finally, the last article in this issue, a theoretical contribution by Erika FischerLichte, brings us back to the heart of Europe, and in particular to some key performances in Germany, where the complex interactions and transgressions between the fictional and the real have been problematized. The 'liminality' that basically exists, she argues, in all forms of theatre, but which she examines in relation to recent performances, mainly in Germany, reveals 'the inability to make sense of what is perceived and to place it in a coherent order'. This sometimes even quite disturbing destabilization of perception has become central to our experience of and in performances.

\section{New developments for TRI}

The international scope of this as well as previous issues of TRI reflects a clear trajectory in contemporary theatre research and performance. Ideas, concepts and approaches in our field have reached a global scope which I hope that the future issues of the journal will be able to address and advance, both empirically and theoretically. This global dimension, which I believe we have not as yet been able to grasp in all its complexities and potentials, clearly signals something important for future research in our field.

In order to explore these potentials further, and in particular to deepen the international scope of TRI, the editors have decided that three new kinds of submission will be introduced, one for each of the three annual issues of the journal. These three kinds of 'dossiers' (as we term and identify them) are as follows:

1 Comprehensive book review articles to reflect research in non-English-speaking areas of the world. Today almost the entire book review sections published in most of the English-language journals in our field, including TRI, are about theatre research in English-speaking contexts and cultures. We therefore encourage researchers from non-English-speaking countries not only to submit book reviews about individual books in various languages, but also to submit more comprehensive reports about the current situation of theatre research in these countries. 
2 In-depth dossiers reporting on new and innovative performance in a language or in an area that would not be immediately accessible to readers of other journals (or of TRI). This dossier could include text and illustrations, interviews with the creators of the performance and critical views and analysis, giving an in-depth coverage instead of just a short performance review. TRI will continue to publish singleauthor full-length articles about performances, but will not publish performance reviews.

3 Reports on new and innovative research projects or programmes undertaken by a group rather than an individual, and preferably where new research is being informed and generated by a cross-generational mix of early-career and senior scholars, or by one of the working groups of IFTR.

Our aim is to include one dossier in each issue of the journal, where each dossier either can contain several shorter contributions by several contributors, or can be a longer, single-authored dossier (in particular for the international book/research reports). Multiauthored contributions should preferably be edited as a dossier prior to submission, and be discussed with TRI editors at an early stage. The length of each dossier, depending of course on its type, content and form, can be that of two journal articles (maximum 10,000 to 12,000 words), but they may also be shorter.

The dossiers will be introduced in the first issue of Volume 34, which goes to press in September 2008, for publication in February 2009. We would like to encourage individuals or groups interested in contributing to this new development to contact us directly and at the earliest opportunity in order to discuss proposals for future publication. 